IZA DP No. 9159

A Model of Dynamic Conflict in Ethnocracies

Dripto Bakshi

Indraneel Dasgupta

June 2015 


\title{
A Model of Dynamic Conflict in Ethnocracies
}

\author{
Dripto Bakshi \\ Indian Statistical Institute \\ Indraneel Dasgupta \\ Indian Statistical Institute \\ and IZA
}

\section{Discussion Paper No. 9159 \\ June 2015}

\author{
IZA \\ P.O. Box 7240 \\ 53072 Bonn \\ Germany \\ Phone: +49-228-3894-0 \\ Fax: +49-228-3894-180 \\ E-mail: iza@iza.org
}

Any opinions expressed here are those of the author(s) and not those of IZA. Research published in this series may include views on policy, but the institute itself takes no institutional policy positions. The IZA research network is committed to the IZA Guiding Principles of Research Integrity.

The Institute for the Study of Labor (IZA) in Bonn is a local and virtual international research center and a place of communication between science, politics and business. IZA is an independent nonprofit organization supported by Deutsche Post Foundation. The center is associated with the University of Bonn and offers a stimulating research environment through its international network, workshops and conferences, data service, project support, research visits and doctoral program. IZA engages in (i) original and internationally competitive research in all fields of labor economics, (ii) development of policy concepts, and (iii) dissemination of research results and concepts to the interested public.

IZA Discussion Papers often represent preliminary work and are circulated to encourage discussion. Citation of such a paper should account for its provisional character. A revised version may be available directly from the author. 
IZA Discussion Paper No. 9159

June 2015

\section{ABSTRACT}

\section{A Model of Dynamic Conflict in Ethnocracies}

We model an infinitely repeated Tullock contest, over the sharing of some given resource, between two ethnic groups. The resource is allocated by a composite state institution according to relative ethnic control; hence the ethnic groups contest the extent of institutional ethnic bias. The contest yields the per-period relative influence over institutions, which partly spills over into the next period, by affecting relative conflict efficiency. Our model generates non-monotone evolution of both conflict and distribution. Results suggest that external interventions, when effective in reducing current conflict and protecting weaker groups, may end up sowing the seeds of greater future conflict.

JEL Classification: D72, D74, O10, O20

Keywords: ethnocracy, ethnic conflict, dynamic contest, rent-seeking, inter-temporal productivity carryover

Corresponding author:

Indraneel Dasgupta

Economic Research Unit

Indian Statistical Institute

203 Barrackpore Trunk Road

Kolkata 700108, West Bengal

India

E-mail: indraneel@isical.ac.in

\footnotetext{
*We thank Parimal Bag and Subhasish Modak Chowdhury for many helpful comments.
} 


\section{Introduction}

In recent years, the concept of ethnocracy has received growing attention in political theory and conflict studies (e.g. Kedar (2003), Yiftachel and Ghanem (2004), Yiftachel (2006) and Howard (2012)). An ethnocracy "is a political system in which political and social organizations are founded on ethnic belonging ... Ethnocracy ... features: 1) political parties that are based foremost on ethnic interests; 2) ethnic quotas to determine the allocation of key posts; and 3) state institutions, especially in education and the security sector, that are segmented by ethnic group. Ethnocracies are generally parliamentary systems with proportional or semiproportional representation according to ethnic classifications. Contrasting political platforms ... are of secondary importance to ethnic-group membership" (Howard, 2012: 155-56). Thus, politics in an ethnocratic state is organized primarily along ethnic lines, with ethnic groups organized to shift resources in their favour. ${ }^{1}$ Key state institutions are ethnicized: they are run by personnel who actively seek to use them to the benefit of their respective ethnic clientele. Control over state institutions therefore complements mass political mobilization in inter-ethnic resource conflicts. Standard examples include Bosnia, Lebanon, Northern Ireland and Belgium (since the 1970s). However, many other countries also exhibit one or more of the abovementioned features or tendencies of the ethnocratic state. ${ }^{2}$

States with strong ethnocratic tendencies often appear also to exhibit watershed points in history, where an initial ethnic settlement, in the sense of an ethnic division of state institutions intended to hold over time, is arrived at. Such initial settlements are often brokered and imposed by militarily dominant external powers. ${ }^{3}$ These settlements are open to subsequent adjustment on the basis of mass political pressure from ethnic mobilizations, but with a temporal lag, and then too, imperfectly. Thus, the outcome of mass ethnic political conflict over resource sharing is influenced

\footnotetext{
${ }^{1}$ As is standard practice in the sociological and comparative-politics literature, we interpret ethnicity broadly as identity cleavages deriving from such non-class categories as language, religion, race, and caste.
}

2 Bosnia has a rotating presidency in which a Croat, a Serb, and a Bosniak are elected to serve concurrent fouryear terms, but with each taking an alternating eight-month turn. In Lebanon, the president is always a Maronite Christian, the parliament speaker a Shia Muslim, and the premier a Sunni Muslim. In Northern Ireland, the first minister and deputy first minister share equal responsibilities, with the former coming from a Unionist (primarily Protestant) party and the latter from a Nationalist (primarily Catholic) party. In Belgium, the Council of Ministers must have equal numbers of Flemish and French speakers. In Lebanon, Bosnia, and Belgium, civilservice posts may be filled via ethnic quotas. In India, caste quotas apply both for seats in state educational institutions and posts in the public sector. For a discussion of Israel and other cases, see the seminal contribution by Yiftachel (2006: esp. chap. 2). Following Howard (2012), we focus on societies where politics is organized around multiple competing ethnic groups (rather than an overwhelmingly dominant one).

3 The US played this role in the Dayton Agreement of 1995 which ended the war in Bosnia. The Good Friday Agreement of 1998 in Northern Ireland was also actively brokered by the US, as was the post-Taliban Afghan political settlement. The last involved a power sharing deal among various ethnic groups, though without explicit ethnic quotas. Lebanon's National Pact of 1943 was imposed by France, the colonial power. The subsequent 1989 Taif Agreement, shaped by Syria, Saudi Arabia, and the US, maintained ethnocratic principles and practices, though amending details. After invading Iraq in 2003, US authorities chose the members of an Iraqi Governing Council along ethno-sectarian lines, roughly matching each group’s share of the population. 
by the current relative ethnic influence within institutions; but this outcome, in turn, affects such influence in future periods, albeit imperfectly. Relative ethnic influence over institutions thus evolves over time as a joint consequence of the initial settlement and ethnic conflict: the evolution of ethnic conflict and inter-ethnic distribution is in turn determined jointly by relative ethnic influence over institutions and relative structural strength of the contending communities.

The purpose of this paper is to develop a simple analytical framework within which this dynamic interaction between ethnic conflict and ethnic control over institutions may be theoretically investigated. We ask two main, policy-relevant, questions. First, how does the initial institutional settlement affect the joint evolution of conflict and horizontal equity, and, thus, social welfare? Second, how does the extent of institutional rigidity with regard to relative ethnic partisanship affect these variables? The first question has important implications for understanding how history, in the sense of policies of past agencies (such as colonialism, absolute monarchies or dictatorships) which governed more or less independently from popular pressures, may exert long-term influence on the joint evolution of conflict and inter-community resource distribution. It also provides useful insights into the long-term consequences of external interventions of contemporary vintage, such as those in Iraq, Afghanistan, Syria or Bosnia, that seek to establish particular forms of ethnic sharing of state institutions. The second question has evident implications for institution design and peace policy in ethnically divided societies. Together, the answers to these questions also permit one to explicate the welfare consequences of perfect institutional neutrality in societies exhibiting ethnocratic tendencies.

We set up a model of a contest, over the sharing of some exogenously given resource, between two combatants, interpreted as two ethnic groups. This resource is allocated by a composite state institution according to relative ethnic control; hence the ethnic groups contest the extent of institutional ethnic bias. This contest is repeated in every period over an infinite number of periods. The contest yields the per-period relative influence over state institutions, and thus, share of the contested resource, according to the standard Tullock (1980) contest success function. Relative influence achieved partly spills over into the next period. ${ }^{4}$ Thus, most crucially, the efficiency with which an ethnic group's conflict inputs can be converted into success outcomes is partly endogenous in our model. It is given by the multiplicative combination of some initial share, interpreted as the degree of control over institutions provided to the ethnic group by a historical original settlement at the beginning of time, and the share acquired in the preceding period's contest. The relative weight on these two elements models the extent to which immediate mass ethnic political mobilizations intended to lobby/pressurize state institutions over short-term resource sharing has long-term effects on the

\footnotetext{
${ }^{4}$ This may happen simply because, as part of the process of pressurizing institutions, ethnic groups manage to insert more of their representatives within institutions, some of whom then maintain their positions into the next period, and/or recruit individuals from their own group. Callander (2007) has shown how bandwagon and momentum might develop in sequential voting, driven by a combination of beliefs and the desire of voters to vote for the winning candidate. Some of these effects may also be present in our very different context, as opportunistic elites adjust their behaviour in line with revealed relative success (power) in mass ethnic conflict.
} 
ethnic bias thereof. A high weight on the former reflects a high degree of institutional rigidity, whereby the relative ethnic partisanship of institutions accords more closely to the original settlement. The combatants have a short time horizon: they discount the future completely. Relative cost of conflict inputs is assumed invariant over time, reflecting structural features of the economy as well as community organization, and one community has a persistent (though possibly minor) cost advantage.

Our model departs from the literature on dynamic contests in its endogenization of the efficiency of contest effort. Baik and Lee (2000) and Lee (2003) set up a model of a two-period contest where efforts in the first period carry over additively into the second period, and players take this spill-over into account in making their first period conflict allocation decisions. Schmitt et al. (2004) maintain this structure while extending it to a finite number (possibly more than two) of periods. Relative efficiency of contest effort of the players is exogenously given in these models. In our infinitely repeated contest, in contrast, relative success in the preceding period determines efficiency in the present period, and players completely discount the future. Maxwell and Reuveny (2005) consider conflict in a dynamic setting, where, as in our model, actors maximize their share of the contested output available in the current period, and this output is split deterministically among the groups based on their fighting effort. Thus, our model is similar to theirs in its assumptions of (a) short (i.e., current period) time horizon of combatants, and (b) conflict outcomes as deterministic shares of the prize. Reuveny et al. (2011) extend this framework to a succession of winner-take-all contests. In both these contributions, however, the spoils are used to increase the sizes of the groups, and the conflict repeats with these altered sizes. Thus, success in the preceding period affects outcomes in the current period only by relaxing the conflict resource constraint, assumed binding, therein. Relative conflict efficiency is exogenously given in these models. In contrast, we assume that conflict resource constraints are non-binding in every period, so that the mechanism through which past conflict affects present conflict in their model becomes inoperative in ours. Instead, past conflict outcomes directly determine relative conflict efficiency in the present in our model. ${ }^{5}$

We find that an initial settlement that does not negate the effort cost advantage of a community in conflict leads to secularly declining conflict, but increasing horizontal inequality. In these cases, a more advantageous initial settlement for the cost-advantaged community reduces conflict, but exacerbates inequality, in every period. This is true of greater institutional flexibility as well. More interestingly, initial ethnic settlements over state institutions that more than negate a community's cost

\footnotetext{
${ }^{5}$ Distantly related is the literature on multi-stage races with farsighted players who compete in a finite sequence of simultaneous move component contests. Konrad and Kovenock (2009) study such a model, where the component contests are all-pay auctions with complete information. Players may win a prize both for winning each component contest and for winning the overall race. They characterize the unique subgame perfect equilibrium. Klump and Polborn (2006) and Irfanoglu et al. (2014) provide related analyses of multi-stage electoral contests. Direct productivity carry-overs and prize sharing, which constitute our focus, do not feature in any of these contributions. On the other hand, unlike theirs, our analysis does not feature either an end state prize or farsighted players. See Konrad (2009, chap. 8) for a survey of the literature on dynamic contests.
} 
advantage in the short run, but are not drastic enough to do so permanently, generate non-monotone evolution of both conflict and distribution. Subsequent to the settlement, conflict increases in initial periods, but declines in later period, asymptotically converging to a steady state. Conversely, intercommunity resource inequality initially declines, and subsequently increases. Hence, a social welfare aggregation of inequality and efficiency (conflict reduction) exhibits non-monotone movement as well. In this zone, a marginal improvement in the low cost community's initial institutional settlement, and in the extent of institutional flexibility, both increase conflict in the initial periods (while reducing inequality), but reduce it in future periods (while increasing inequality). This situation appears to be most likely in real historical contexts. In these contexts, (a) welfare comparisons of alternative intervention packages require specification of both the normatively chosen trade-off between efficiency and equity and the time discount factor, and (b) such comparisons may be time inconsistent. Perfect institutional neutrality facilitates neither equity nor efficiency.

Our results have important implications for the debate over 'liberal interventionism'. Such interventions by foreign entities are often sought to be politically justified by the jointly stated goal of conflict reduction and protection of weaker ethnic groups, within a context of growing ethnic conflict. It is natural to expect politicians and voters in countries which are in a position to intervene to have short time horizons: they are likely to prioritize immediate conflict reduction over long-term peace building. Our results suggest that higher levels of short term peace and protection of weaker ethnic groups may be ensured by one-off interventions which impose a combination of higher institutional disadvantage and greater institutional rigidity on the ethnic group with a conflict cost advantage. However, such higher levels of short term conflict reduction are purchased at the cost of deeper conflict in the longer term. Thus, political short-termism in intervening countries is likely to bias peace-building interventions towards forms (specifically, greater institutional locking out of the stronger/dominant group post intervention and greater institutional rigidity with regard to emergent ethnic political pressure) that are likely to exacerbate conflict in the future. Such exacerbation in turn is likely to justify demands for continuing, deeper and more long-standing intervention, as for example has been the case in Iraq, Syria and Afghanistan, which would push the problem further into the future. Thus, our model suggests that external interventions, when effective in reducing current conflict and protecting weaker groups, may in fact end up sowing the seeds of greater future conflict.

Section 2 sets up the model. Section 3 discusses how greater institutional flexibility with regard to ethnic pressures affects the joint evolution of conflict and resource distribution. Section 4 extends the analysis to an explicit consideration of trade-offs between (horizontal) equity and efficiency (conflict reduction) by embedding it within an aggregative welfare framework. Section 5 discusses some implications for peace policy. Section 6 offers concluding remarks. Detailed proofs of propositions are relegated to an appendix. 


\section{The model}

Consider a scenario where two groups (ethnic communities), A and B, are engaged in contestation over some income-generating resource in every period $t \in\{1,2,3, \ldots\}$. The per-period monetary value of the resource being contested over, to community $i \in\{A, B\}$, is $p_{i}>0$, and its population size is $n_{i}$. Thus, the item being contested over is simply something (e.g. agricultural land, natural (esp. mineral) resources, or foreign aid flows) which, if possessed by community $i$, would generate income $p_{i}$ in every period for that community. Note that communities may (but need not) differ in their valuation of the good being contested. ${ }^{6}$ The resource is allocated by a composite state institution (legislature, bureaucracy, armed forces and law courts). This composite state institution's decisions regarding the ethnic division of the resource is determined by a process of contestation (lobbying, political pressure, mass mobilization, direct street action, violence, etc.). Given any group $i \in\{A, B\}$, we shall denote the other group by $-i$. $\quad M_{i t} \geq 0$ is some non-contested, or productive, income accruing to each member of $i$ in period $t$. For community $i \in\{A, B\}$ in period $t \in\{1,2,3, \ldots\}$, the proportion of the state institution's decisions that act in its favour, and, thus, the share of the prize, is given by the following variant of the standard (Tullock, 1980) contest success function:

$$
\begin{aligned}
& s_{i t}=\frac{s_{i, 0}^{1-\theta} s_{i, t-1}{ }^{\theta} x_{i t}}{s_{i, 0}^{1-\theta} s_{i, t-1} x_{i t}+s_{-i, 0}^{1-\theta} s_{-i, t-1}{ }^{\theta} x_{-i, t}} \text { if } x_{t}>0 ; \\
& s_{i t}=\frac{s_{i, 0}^{1-\theta} s_{i, t-1} \theta}{s_{i, 0}^{1-\theta} s_{i, t-1} \theta+s_{-i, 0}^{1-\theta} s_{-i, t-1}} \text { otherwise; }
\end{aligned}
$$

where $x_{i t}, x_{-i t}$, respectively, denote the total amounts of conflict input (or, activist labour) allocated by communities $i$ and $-i$ in period $t ; x_{t} \equiv x_{i t}+x_{-i, t}, x_{i t}, x_{-i t} \geq 0$, and $\theta \in(0,1)$. From (1),

$$
\begin{aligned}
& s_{i t}=\frac{x_{i t}}{x_{i t}+s_{-i, i, 0}{ }^{1-\theta} s_{-i, i, t-1} x_{-i, t}} \text { if } x_{t} \neq 0, \\
& =\frac{1}{1+s_{-i, i, 0}{ }^{1-\theta} S_{-i, i, t-1} \theta} \text { otherwise; }
\end{aligned}
$$

where $s_{-i, i, 0} \equiv \frac{s_{-i, 0}}{s_{i, 0}} ; s_{-i, i, t-1} \equiv \frac{s_{-i, t-1}}{s_{i, t-1}}$. The formulation in (2) clarifies the intuitive idea that the parameter $\theta$ captures the extent of inter-temporal spill-overs in conflict. When $\theta=0$, the model reduces to the standard case of no spill-overs across battlefields (i.e., over time). Relative efficiency of conflict input for community B is given simply by its initial relative institutional share $s_{B A, 0}$, and

\footnotetext{
${ }^{6}$ Differences in valuation of the item under contestation may reflect differential sales opportunities in global markets (as when international sanctions on oil or diamond sales from conflict zones differentially impact different ethnic militias) and/or possession of productivity enhancing complementary inputs such as technical personnel, ports and transport networks. Additionally, when one community has greater uncontested possession of a similar resource, say oilfields or mines, the contested resource may be more valuable to that community due to economies of scale and indivisibilities in commercial exploitation.
} 
this remains invariant over time. When $\theta>0$, positive spill-overs exist: success in one period acts, in effect, as a force multiplier in the next. To see this, suppose, without loss of generality, that $s_{B A, t-1} \equiv \frac{s_{B, t-1}}{s_{A, t-1}}>1$, so that B is more successful in the period preceding $t$. Then, for all $\theta>0$, $s_{B A, t-1}{ }^{\theta}>1$; furthermore, $s_{B A, t-1}{ }^{\theta}$ is monotonically increasing in $\theta$. Thus, greater success in the preceding period magnifies the effectiveness or productivity of one's conflict inputs in the current period, thereby translating into a higher success (i.e., share) in that period for any given deployment of conflict inputs therein by the two parties, and for any initial history $s_{B A, 0}$. The higher the value of $\theta$, the greater the extent of productivity spill-over from the immediate past to the present, and, correspondingly, the lower the importance of initial conditions in determining present conflict efficiency. In the limit $\theta=1$, initial history ceases to matter completely in the determination of relative conflict efficiency. Conversely, spill-overs from the immediate past to the present act as a force dampener in the present for the combatant relatively less successful in the preceding period.

Community $i \in\{A, B\}$ in period $t$ can purchase conflict inputs in that period, at a price $q_{i t}$, which reflects the (broadly market determined) composite cost of training, equipping and retaining a unit of activist labour. Formally, we think of a unit of conflict input as one unit of activist labour, produced by the (cost-minimizing) combination of raw labour with specialized training and enabling equipment according to some linearly homogeneous production function, the latter being determined by the specific form of the conflict (e.g. whether lobbying, mass street mobilization or political violence). Given a linearly homogeneous production function, the conflict cost, $q_{i t}$, can thus be thought of as the (constant) marginal cost of output (activist labour), determined in standard fashion by the cost-minimizing input combination weighted by the market determined prices of all inputs. ${ }^{7}$ Among the multiple determinants of a group's conflict cost, perhaps the most important ones are: (i) the extent of the group's access to the international market for military goods, including mercenaries and military trainers, and (ii) the domestic (group-specific) return from productive labour.

Apart from training and equipment, however, the conflict efficiency of a unit of activist labour may be expected to be affected positively by support from elites who control the institutions of state

\footnotetext{
${ }^{7}$ Intuitively, to participate effectively in conflict, each potential activist in a group needs to be first trained to some level to carry out activities pertaining to lobbying, propaganda, agitation, organization, violent confrontation, terrorism and/or civil war. Additionally, she has to be provided with some requisite level of material and human support equipment, say office space, transport and communication facilities, printing press, legal aid, safe houses, and/or armament. In both cases, costly material goods and human services, largely available at short notice through local or global markets, need to be purchased. Lastly, the activist has to be provided sufficient financial inducement to make her decision to participate in conflict activities individually rational: the magnitude of such payment would thus depend on her returns from productive activities. The human element in activism may be substituted to a large extent by better training or more material equipment: the cost minimizing combination will thus be determined by technology and relative prices. Arbatskaya and Mialon (2010) provide a formalization of this basic idea of multiple conflict inputs mapped (according to a Cobb-Douglas production function in their case) into an aggregate conflict effort variable.
} 
power (the military, police, bureaucracy, and the judiciary). These institutions control access to items which, while not easy to procure from market purchase, can nonetheless complement activist labour in conflict situations. Sympathetic generals can provide access to existing stocks of heavy weaponry, supportive officials may easily concede demands from $i$ but refuse to accede to political pressure from its rival, and partisan police officers and judges may refuse to act against activists from one community while clamping down heavily on those from the other. Thus, the relative efficiency, in mass political conflict to influence state institutions, of a unit of activist labour belonging to a community should be an increasing function of its relative control over elites who run institutions.

Mass ethnic political movements commonly seek to pressurize the state to simultaneously accede to its current resource demands and to increase its representation within state institutions which actually implement allocations at the ground level. ${ }^{8}$ We therefore think of each contending community as using activist labour to pressurize those elite individuals who are not its natural sympathizers to act in its favour within institutions, as in the standard literature on lobbying and rentseeking. Additionally, each contending community also uses activist labour to pressurize the state to increase its representation within state institutions. If institutions were completely subordinate to pressures from mass politics, their personnel composition should fully adjust to, or accommodate, the relative strength of the contending groups, as revealed by the relative conflict success ratio. Thus, A's relative control over institutions in period $t$ would be identical to its relative conflict success in the preceding period $\left(\frac{s_{A, t-1}}{s_{B, t-1}}\right)$. Recalling (2), this corresponds to our conflict success function when $\theta=1$ : intuitively, this corresponds to the idea of perfectly flexible institutions, i.e., institutions completely and accurately reflecting the prevailing ethnic balance of power in the mass political sphere.

Realistically, however, one would expect ethnic accommodation to be less than perfect. It is well-known in the political science literature that elites are self-perpetuating to a significant extent. Institutions such as the military, bureaucracy, police, and judiciary all have their internal hierarchies, specialized personnel requirements and relatively autonomous recruitment rules, which politicians representing mass movements find difficult to alter dramatically without risking elite resistance and consequent governance collapse in the short run. Thus, the ability of elites to resist political attempts at permanently restructuring their social composition or long-term ethnic alignment implies that institutions are likely to exhibit a certain rigidity: they are likely to exhibit a measure of relative community bias that lags behind the immediately revealed relative political strength. This consideration motivates and justifies the assumption $\theta \in(0,1)$. To see this more clearly, assume $\mathrm{A}$ is the weaker community in ethnic contestation in some period relative to the initial institutional

8 To illustrate, recent street demonstrations in US cities against police treatment of African-Americans demanded both changes in police practice and greater representation of African-Americans in the upper levels of the law-enforcement hierarchy. 
settlement, i.e. $\frac{s_{A, t-1}}{s_{B, t-1}}<\frac{s_{A, 0}}{s_{B, 0}}$. Notice that, for $\theta \in(0,1)$, (i) $\left[\frac{s_{A, 0}}{s_{B, 0}}>\left(\frac{s_{A, 0}}{s_{B, 0}}\right)^{1-\theta}\left(\frac{s_{A, t-1}}{s_{B, t-1}}\right)^{\theta}>\frac{s_{A, t-1}}{s_{B, t-1}}\right]$, and (ii) $\left[\frac{s_{A, 0}}{s_{B, 0}}-\left(\frac{s_{A, 0}}{s_{B, 0}}\right)^{1-\theta}\left(\frac{s_{A, t-1}}{s_{B, t-1}}\right)^{\theta}\right]$ is increasing in $\theta$. Thus, $\theta \in(0,1)$ implies that A's weakness in mass politics in the immediate past does translate into its relative weakness within institutions in the present, but only partially: institutional elites maintain independence from the immediately dominant community, $\mathrm{B}$, to an extent. A lower value of $\theta$ implies a higher degree of elite conformity to the original balance of power $\left(s_{B A, 0}\right)$ while, conversely, a higher value of $\theta$ implies elites (and thereby institutions) more accommodative of immediate political strength. The polar case of $\theta=0$ models perfect elite (and thereby, institutional) rigidity: the institutional balance of power rigidly conforms to the initial settlement regardless of the outcome in the subsequent ethnic conflicts. States such as Lebanon and Northern Ireland, where ethnic division of control over institutions currently follows relatively rigid rules codified in some past settlement (respectively, French colonialism imposed rules and the Good Friday Agreement), may, for modelling purposes, be thus ascribed values of $\theta$ close to 0. Conversely, states such as India, Israel, Belgium, South Africa and Iraq, where in recent years the relative presence of ethnic groups within institutions has changed significantly in response to mass political pressure, may be modelled as involving relatively high values of $\theta .^{9}$

Remark 1. Full and persistent institutional neutrality between contending groups is ensured when $s_{A B, 0}=1$ and $\theta=0$. Thus, complete institutional rigidity coupled with an initial settlement which ethnicizes institutions equally between the contending groups, say through constitutional and juridical provisions of mandatory equal representation, ensures institutional neutrality in our model.

Remark 2. Institutional rigidity (low $\theta$ ) may be the de facto outcome even in the absence of de jure rules codified in past institutional settlements. Recall that institutional rigidity comes about when the ethnic composition of elites running state institutions is relatively impervious to change. Running institutions usually requires at least a minimal level of specialized, technocratic knowledge, training and experience. When education levels vary dramatically between ethnic groups, the better educated ethnic group may continue to dominate in state institutions simply because very few members of the other group achieve the minimal educational qualifications necessary to meet the entry

\footnotetext{
${ }^{9}$ In India, since Independence, recruitment quotas in the bureaucracy, police and the public sector have been progressively extended: initially to the so-called Scheduled Castes and Tribes, subsequently to Other Backward Castes, and, most recently, to sections of Muslims. The passing of the relevant legislation, and the extent of its subsequent implementation, have both reflected the fluctuating strength of mass ethnic political lobbies. Affirmative action in South Africa since the end of Apartheid, ethnic representation in Belgian institutions since the 1970s, minority ethnic rights in Israel since 1990, Sunni representation in state institutions in Iraq in the past decade, have all similarly evolved and changed significantly in response to mass ethnicizing political pressures. In these cases, the patterns of institutional ethnicization appear to be determined more by immediate and evolving ethnic politics than the terms of some original ethnic settlement.
} 
requirements. $^{10}$ On the other hand, the less educated ethnic group is likely to have a lower opportunity cost of activist labour and thus a conflict cost advantage.

Following Maxwell and Reuveny (2005) and Reuveny et al. (2011), we assume that individuals, and therefore communities, have a short time horizon: they completely discount future periods in their allocation decisions. As argued there, it is implausible to ascribe long time horizons to real-life political actors in situations of conflict stretching indefinitely into the future. Additionally, this feature of the model serves to isolate, and thereby highlight, the role of impersonal inter-temporal spill-overs in influencing conflict outcomes over time. We also assume that communities follow an equal surplus sharing rule, whereby each member of a community $i \in\{A, B\}$ receives an equal share of that community's net income (i.e., the amount $\frac{\left[s_{i t} p_{i}-q_{i t} x_{i t}+n_{i} M_{i t}\right]}{n_{i}}$ ) in each period. Thus, it is individually rational to maximize total community income. We can therefore abstract from free-rider problems within a community to model each community as an individual combatant seeking to maximize its total income in each period, $\left[s_{i t} p_{i}-q_{i t} x_{i t}+n_{i} M_{i t}\right]$, subject to the conflict success function (1) above. ${ }^{11}$ Our formulation also abstracts from conflict financing issues, which is the focus of much of the literature on conflicts in multiple battlefields (e.g. Maxwell and Reuveny (2005), Kvasov (2007) and Reuveny et al. (2011); see Kovenock and Roberson (2012) for a recent survey).

Remark 3. One could, alternatively, follow Katz et al. (1990) in modelling the contested resource as a group-specific public good, which yields $p_{i}$ to each member $j \in\left\{1,2, \ldots, n_{i}\right\}$ of community $i$, and assume that all individuals simultaneously choose their individual conflict input contributions $x_{j i, t}$ so as to maximize individual payoffs $\left[s_{i t} p_{i}-q_{i t} x_{j i, t}+M_{i t}\right]$, with total conflict allocation of a community simply the sum of individual contributions, i.e. $x_{i t} \equiv \sum_{j=1}^{n_{i}} x_{j i, t}$. The first order conditions remain identical under this alternative, yielding (3) below. Consequently, our conclusions presented below will continue to hold in substance.

Using (2), for period $t$, recalling that the relative conflict outcome share is denoted by: $s_{B A, t} \equiv \frac{s_{B t}}{s_{A t}}$, the first order conditions yield:

$$
\frac{\left(s_{B A, 0}\right)^{1-\theta}\left(s_{B A, t-1}\right)^{\theta} x_{B t}}{\left[x_{A t}+\left(s_{B A, 0}\right)^{1-\theta}\left(s_{B A, t-1}\right)^{\theta} x_{B t}\right]^{2}}=\frac{q_{A t}}{p_{A}} \equiv C_{A t},
$$

\footnotetext{
10 For example, despite recruitment quotas in their favour since Independence, representation of the so-called Scheduled Castes and Tribes remains far short of both their quota levels and population shares in middle to upper level positions in the bureaucracy, police and the public sector in India. Reserved posts remain vacant due to the paucity of candidates meeting minimum requirements. See Varma (2012).

11 Dasgupta and Kanbur (2011, 2007 and 2005a) have argued that mutual benefit from sharing of group-specific public goods, generated by decentralized voluntary contributions of group members, may play an important role in reducing welfare inequality, conflict and opportunistic behaviour within a group.
} 


$$
\frac{\left(s_{B A, 0}\right)^{1-\theta}\left(S_{B A, t-1}\right)^{\theta} x_{A t}}{\left[x_{A t}+\left(s_{B A, 0}\right)^{1-\theta}\left(S_{B A, t-1}\right)^{\theta} x_{B t}\right]^{2}}=\frac{q_{B t}}{p_{B}} \equiv C_{B t}
$$

where $C_{i t}$ is the ratio of the per unit conflict cost to benefit. Together, (3) and (4) yield:

$$
\frac{x_{B t}}{x_{A t}}=\frac{q_{A B t}}{p_{A B}} \equiv C_{A B, t}
$$

where $q_{A B, t} \equiv \frac{q_{A t}}{q_{B t}}$ is the relative cost of deploying a unit of the conflict input, while $p_{A B} \equiv \frac{p_{A}}{p_{B}}$ is the relative benefit from acquiring the item under contestation, and $C_{A B, t} \equiv \frac{C_{A t}}{C_{B t}}$. Thus, the variable $C_{A B, t}$ measures the relative cost of conflict inputs for A, normalized by the relative benefit to A from acquiring the item under contestation. Using (3)-(5), we have individual conflict input deployments in $t$ for any given value of the relative share in period $t-1$ and the initial balance of power:

$$
\begin{aligned}
& x_{A t}=\frac{\left(s_{B A, 0}\right)^{1-\theta}\left(S_{B A, t-1}\right)^{\theta}}{C_{B t}\left[1+\left(s_{B A, 0}\right)^{1-\theta}\left(S_{B A, t-1}\right)^{\theta} C_{A B, t}\right]^{2}} ; \\
& x_{B t}=\frac{\left(s_{B A, 0}\right)^{1-\theta}\left(S_{B A, t-1}\right)^{\theta} C_{A B, t}}{C_{B t}\left[1+\left(s_{B A, 0}\right)^{1-\theta}\left(S_{B A, t-1}\right)^{\theta} C_{A B, t}\right]^{2}} .
\end{aligned}
$$

Together, (6)-(7) yield total conflict expenditure in battlefield (period) $t$ :

$$
E_{t} \equiv q_{A t} x_{A t}+q_{B t} x_{B t}=\frac{\left(s_{B A, 0}\right)^{1-\theta}\left(S_{B A, t-1}\right)^{\theta}}{\left[1+\left(s_{B A, 0}\right)^{1-\theta}\left(S_{B A, t-1}\right)^{\theta} C_{A B, t}\right]^{2}}\left[\frac{q_{A t}+C_{A B, t} q_{B t}}{C_{B t}}\right] .
$$

$E_{t}$ provides a measure of both the intensity of conflict and the extent of social wastage thereby in a period; (6)-(7) yield the relative share in $t$ as a function of that in the preceding and initial periods:

$$
s_{B A, t}=\left(s_{B A, 0}\right)^{1-\theta}\left(s_{B A, t-1}\right)^{\theta} \frac{x_{B t}}{x_{A t}}=\left(s_{B A, 0}\right)^{1-\theta}\left(s_{B A, t-1}\right)^{\theta} C_{A B, t} .
$$

Using (9) and recalling that $s_{B A, t} \equiv \frac{s_{B t}}{s_{A t}}, s_{B t}+s_{A t}=1$, we get:

$$
\begin{aligned}
& s_{A t}=\left[\left(s_{B A, 0}\right)^{1-\theta}\left(s_{B A, t-1}\right)^{\theta} C_{A B, t}+1\right]^{-1}=\frac{1}{s_{B A, t}+1}, \\
& s_{B t}=\frac{\left(s_{B A, 0}\right)^{1-\theta}\left(s_{B A, t-1}\right)^{\theta} C_{A B, t}}{\left[\left(s_{B A, 0}\right)^{1-\theta}\left(s_{B A, t-1}\right)^{\theta} C_{A B, t}+1\right]}=\frac{s_{B A, t}}{s_{B A, t}+1} .
\end{aligned}
$$

Repeated use of (9) yields:

$$
S_{B A, t}=s_{B A, 0}\left[C_{A B, 1} \theta^{t-1} C_{A B, 2} \theta^{t-2} \ldots C_{A B, t-1}{ }^{\theta} C_{A B, t}\right] .
$$

The initial settlement, $s_{B A, 0}$, and hence relative ethnic control over institutions in period 1 , is a parameter in our model. The community-specific costs of conflict inputs are like-wise given, reflecting structural conditions in the economy (which determine the opportunity cost of converting 
productive labour to activist labour) and/or the extent of access to global arms and mercenary markets. Traditional forms of social organization, such as caste, clan or religious institutions, as well as norms of behaviour such as mandatory participation in collective annual festivals or pilgrimage, may reduce or enhance the transaction and search costs associated with recruiting and training activist labour, and organizing conflict activities in general. Variations in the functioning of such structures across communities may thus contribute to differences in conflict costs. ${ }^{12}$

Assumption 1. For all $t \in\{1,2,3, \ldots\},,\left[q_{A B, t}=\bar{q}_{A B}\right]$, with $\frac{\bar{q}_{A B}}{p_{A B}}>1$.

Assumption 1 restricts attention to the case where the relative cost of military inputs is constant over time, and A has a (benefit-normalized) cost disadvantage. Intuitively, one community may have a persistent normalized cost advantage in conflict when its opportunity cost of deploying activist labour is lower (say, because it controls land that is less fertile or has a larger pool of unemployed), or when some external government/agency such as the US, NATO or the EU secularly subsidizes retention, training and equipment expenses, including arms, for its activist labour, or when it is better placed to financially exploit the contested item. One community may also have traditional internal institutions that are better at providing ready sites of activist recruitment and training.

Let $\bar{C}_{A B} \equiv \frac{\bar{q}_{A B}}{p_{A B}}$ be the normalized relative cost. Given Assumption 1, (11) yields:

$$
\text { for all } t \in\{0,1,2,3, . .\}, s_{B A, t}=s_{B A, 0}\left(\bar{C}_{A B}\right)^{\left(\frac{1-\theta^{t}}{1-\theta}\right)} \text {. }
$$

By (12), higher $s_{B A, 0}$ implies greater $s_{B A, t}$ in every period $t$. Thus, an initial positive shock to a combatant's share gets transmitted over time: it causally generates greater share in every future period due to the productivity advantage it confers. Hence history, modelled as an initial division of control over institutions, exerts a permanent influence in our model. From (12),

$$
\lim _{t \rightarrow \infty} S_{B A, t}=s_{B A, 0}\left(\bar{C}_{A B}\right)^{\left(\frac{1}{1-\theta}\right)} .
$$

Equation (13) shows that the degree of institutional flexibility with regard to ethnic influences, as measured by the parameter $\theta$, continues to influence the relative share even in the limit. Initial

\footnotetext{
${ }^{12}$ The impact of population size on conflict cost appears intuitively ambiguous. Larger community size is likely to provide a larger pool of individuals better endowed with innate psychological and physical abilities ('aggression') that can be substituted for costly training in the production of activist labour. However, as is commonly argued, larger communities may also find it more difficult to maintain community cohesion and prevent free-riding (see, for example, Olson (1965), Hardin (1982) and Esteban and Ray (2001)).
} 
conditions, as measured by the initial ethnicization ratio $s_{B A, 0}$, do so as well. The relative share asymptotically converges to the steady state level, $s_{B A, 0}\left(\bar{C}_{A B}\right)^{\frac{1}{1-\theta}}$. Lastly, since $\theta \in(0,1)$, (12) yields:

$$
\text { for all } t \in\{1,2,3, \ldots\}, \frac{s_{B A, t+1}}{s_{B A, t}}=\left(\bar{C}_{A B}\right)^{\theta^{t}} \text {. }
$$

We can now characterize the movement of the relative share of the contested resource, and the consequent pay-offs, over time. Together, (12)-(14) immediately yield the following.

Proposition 1. Let Assumption 1 hold. Then $s_{B A, t}$ is monotonically increasing, at a decreasing rate, over time; $s_{B A, t}$ converges to $s_{B A, 0}\left(\bar{C}_{A B}\right)^{\frac{1}{1-\theta}}$.

$\overline{\mathrm{C}}_{\mathrm{AB}}>1$ by Assumption 1. The relative share of $\mathrm{B}$ then increases over time, adjusting monotonically (and asymptotically) towards its steady state level $\left(s_{B A, 0}\left(\bar{C}_{\mathrm{AB}}\right)^{\frac{1}{1-\theta}}\right)$. Analogous results follow for the pay-offs to the two communities, as we proceed to summarize in Corollary 1 below.

From (6), (7), (9) and (10), ignoring the uncontested part $n_{i} M_{i t}$, we get the contest pay-off for each community per period, net of conflict cost:

$$
\text { for all } t \in\{1,2,3, \ldots\} ; F_{A, t}=\frac{p_{A}}{\left[s_{B A, t}+1\right]^{2}}, F_{B, t}=\frac{p_{B}}{\left[1+\frac{1}{s_{B A, t}}\right]^{2}} \text {. }
$$

Notice that, by (15), returns from engaging in conflict, net of costs, are positive: thus, conflict does not exhaust the entire prize. In light of (15), Proposition 1 yields the following.

Corollary 1. Let Assumption 1 hold. Then $F_{A, t}$ is monotonically decreasing and $F_{B, t}$ is monotonically increasing over time. $F_{A, t}$ converges to $\frac{p_{A}}{\left[s_{B A, 0} \bar{c}_{A B} \frac{1}{1-\theta}+1\right]}$, while $F_{B, t}$ converges to $\frac{p_{B}}{\left[1+\frac{1}{s_{B A, 0} \bar{c}_{A B} \frac{1}{1-\theta}}\right]^{2}}$

Lastly, consider the behaviour of total expenditure on conflict by the two communities. Rearranging the expression in (8), and using (9), total expenditure on conflict is given by: 


$$
E_{t}=\frac{\left(p_{A}+p_{B}\right)}{\left[\frac{1}{s_{B A, t^{\frac{1}{2}}}}+\left(s_{B A, t}\right)^{\frac{1}{2}}\right]^{2}} .
$$

Recalling (13), (16) yields:

$$
\lim _{t \rightarrow \infty} E_{t}=\frac{\left(p_{A}+p_{B}\right)}{\left[\frac{1}{s_{B A, 0}^{\frac{1}{2}\left(\bar{C}_{A B}\right)^{\frac{1}{2(1-\theta)}}}}+s_{B A, 0}{ }^{\frac{1}{2}}\left(\bar{C}_{A B}\right)^{\frac{1}{2(1-\theta)}}\right]^{2}} .
$$

Equation (16) implies that total conflict increases in $S_{B A, t}$ in the $(0,1)$ interval, attains its maximum at $S_{B A, t}=1$, and subsequently declines in $S_{B A, t}$. Recalling that, by (12), $s_{B A, 2}=s_{B A, 0} \bar{C}_{A B}{ }^{1+\theta}$, (16), (17) and Proposition 1(ii) immediately yield the following.

Corollary 2. Let Assumption 1 hold. Then total (per-period) expenditure on conflict:

(i) converges to $\frac{\left(p_{A}+p_{B}\right)}{\left[\frac{1}{s_{B A, 0}^{\frac{1}{2}}\left(\bar{C}_{A B}\right)^{\frac{1}{2(1-\theta)}}}+s_{B A, 0^{\frac{1}{2}}}\left(\bar{C}_{A B}\right)^{\frac{1}{2(1-\theta)}}\right]^{2}}$;

(ii) monotonically increases over time if $s_{B A, 0} \bar{C}_{A B}\left(\frac{1}{1-\theta}\right) \leq 1$;

(iii) monotonically decreases over time if $s_{B A, 0} \bar{C}_{A B} \geq 1$; it first increases and subsequently decreases if $\quad\left[s_{B A, 0} \bar{C}_{A B}{ }^{\left(\frac{1}{1-\theta}\right)}>1 \quad\right.$ and $\left.\quad s_{B A, 0} \bar{C}_{A B}{ }^{1+\theta}<1\right]$.

By Corollary 2(ii), social waste from conflict increases over time if the limiting value of $s_{B A, t}$ does not exceed unity, as the success ratio monotonically increases to approach its steady state (Proposition 1(ii)). By Assumption 1, B has a relative (normalized) cost advantage. Thus, Corollary 2(ii) implies that conflict increases secularly if the initial settlement puts the community with the lower conflict cost at a great disadvantage. Corollary 2(iii) implies that conflict decreases secularly if the period 1 relative share of $\mathrm{B}$ is not less than the conflict-maximizing value of unity. The most interesting case obtains if the initial (period 1) relative share of B is less than its conflict-maximizing value of unity, but its steady state value is greater than unity. Then conflict first increases (over $\left(s_{B A, 1}, 1\right)$ ), eventually reaching its peak, and declines subsequently (over $\left(1, s_{A B, 0} \bar{C}_{A B}\left(\frac{1}{1-\theta}\right)\right.$ )). The relative share of B increases asymptotically towards its steady state value of $s_{A B, 0} \bar{C}_{A B}\left(\frac{1}{1-\theta}\right)$ (Proposition 1(i)). 


\section{Conflict and institutional accommodation}

We now proceed to specify how the extent of inter-temporal institutional accommodation of mass ethnic pressures affects the evolution of conflict and the distribution of contested income over time.

Proposition 2. Let Assumption 1 hold.

(i) For all $t \in\{2,3, \ldots\}, \frac{\partial s_{B A, t}}{\partial \theta}, \frac{\partial F_{B t}}{\partial \theta}>0, \frac{\partial F_{A t}}{\partial \theta}<0$.

(ii) $\lim _{t \rightarrow \infty, \theta \rightarrow 1} s_{B A, t}=\infty, \lim _{t \rightarrow \infty, \theta \rightarrow 1} F_{B, t}=p_{B}$ and $\lim _{t \rightarrow \infty, \theta \rightarrow 1} F_{A, t}=0$.

(iii) $\frac{\partial E_{t}}{\partial \theta}<0$ for every period $t \in\{2,3,4, \ldots\}$ if $s_{B A, 0} \bar{C}_{A B}{ }^{1+\theta}>1$; $\frac{\partial E_{t}}{\partial \theta}>0$ for every period $t \in$ $\{2,3,4, \ldots\}$ if $s_{B A, 0} \bar{C}_{A B}{ }^{\frac{1}{1-\theta}} \leq 1$; if $\left[s_{B A, 0} \bar{C}_{A B}{ }^{1+\theta}<1\right.$ and $\left.s_{B A, 0} \bar{C}_{A B}{ }^{\frac{1}{1-\theta}}>1\right]$, then there exists $t^{*} \in$ $\{3,4,5, \ldots\}$ such that $\left[\frac{\partial E_{t}}{\partial \theta}>0\right.$ if $\left.2 \leq t<t^{*}\right]$ and $\left[\frac{\partial E_{t}}{\partial \theta}<0\right.$ if $\left.t>t^{*}\right]$.

(iv) $\lim _{t \rightarrow \infty, \theta \rightarrow 1} E_{t}=0$.

Proof: See the Appendix.

By Proposition 2(i), greater institutional flexibility magnifies B's cost advantage, increasing both B's success and pay-off in every period beyond the first. Proposition 2(ii) shows that an infinitesimally small cost advantage for B suffices to make that community's relative pay-off converge to an arbitrarily high value when the extent of institutional flexibility is sufficiently close to unity. Thus, the mediation of high institutional pliability translates even minor cost advantages into major pay-off gains over time. Parts (iii) and (iv) of Proposition 2 show that greater institutional accommodation has ambiguous (non-monotone) consequences for conflict. When one community has even a minimal cost advantage, a sufficiently high degree of institutional malleability serves to make conflict converge to an arbitrarily low level. If the initial settlement does not disadvantage the low cost combatant, B, too much (if at all) relative to its cost advantage, so that it receives the higher share in period $2\left(s_{B A, 2}=s_{B A, 0} \bar{C}_{A B}{ }^{1+\theta}>1\right)$, any increase in institutional flexibility, by expanding B's dominance, reduces aggregate conflict. However, if the initial settlement counteracts B's cost advantage so much that $\mathrm{B}$ always receives the lower share, a marginal increase in institutional flexibility, by reducing A's dominance, increases conflict in every period. Now consider the intermediate case where the initial settlement counteracts B's cost advantage to a limited extent, so 
that $\mathrm{B}$ receives the lower share in initial periods but the higher share in later periods. Then, a marginal rise in institutional flexibility increases conflict initially, while reducing it in later periods.

Consider an initial settlement which more than negates the cost advantage of community B, so that it receives the lower share in period $1\left(s_{A B, 0} \bar{C}_{A B}<1\right)$. Starting from an initial situation of complete institutional rigidity $(\theta=0)$, consider an increase in institutional flexibility $(\theta)$. For relatively low levels of institutional flexibility, the steady state relative share of $\mathrm{B}\left(s_{A B, 0} \bar{C}_{A B} \frac{1}{1-\theta}\right)$ remains below 1. In this range, any increase in institutional flexibility increases B's share and pay-off, as well as aggregate conflict, while reducing A's share as well as pay-off, from period 2 onwards.

Further increase in $\theta$, while keeping the period 2 relative share of $\mathrm{B}\left(s_{A B, 0} \bar{C}_{A B}{ }^{1+\theta}\right)$ below unity, pushes the steady state relative share of $\mathrm{B}\left(s_{A B, 0} \bar{C}_{A B} \frac{1}{1-\theta}\right)$ above 1 . These two conditions will hold simultaneously for a range of $\theta$. Increases in institutional flexibility in this range will increase conflict in initial periods while reducing it in later periods; B's share and pay-off will increase, and A's pay-off fall, throughout. If $s_{A B, 0} \bar{C}_{A B}{ }^{2}>1$, then there must exist a range of values of $\theta$ close to 1 for which $\mathrm{B}$ receives the higher share in every period from 2 onwards. In this range, an increase in $\theta$ will reduce conflict in every period. Notice that such a range will not exist if the initial settlement sufficiently negates B's cost advantage. Thus, in sum, Proposition 2(iii) implies that greater institutional responsiveness to ethnicizing political pressures involves an explicit trade-off between efficiency (in the sense of reducing social wastage due to conflict) and equity across the communities; its impact on either of these two policy goals is however non-monotone.

Remark 4. Perfect and persistent institutional neutrality $\left(s_{B A, 0}=1\right.$ and $\theta=0$; recall Remark 1) serves neither equity nor efficiency: from (12) and (15), equity is improved in every period by marginally altering the initial settlement in favour of A (i.e., by reducing $s_{B A, 0}$ ), while, by (12) and (16), efficiency is improved by increasing the degree of institutional flexibility when $s_{B A, 0}=1$.

\section{Conflict and social welfare}

We now clarify further the trade-off between equity and efficiency (conflict reduction) identified above, by embedding the analysis within a social welfare calculus. We also show how this trade-off, and thus social welfare, is affected by permanent changes in the relative cost advantage and the extent of institutional flexibility, as well as by short-term (i.e. one-off) conflict success shocks.

Let per period social welfare be given by a symmetric CES function of community pay-offs:

$$
W_{t}=\left[F_{A t}^{\sigma}+F_{B t}{ }^{\sigma}\right]^{\frac{1}{\sigma}}
$$


where $\sigma \in(-\infty, 0) \cup(0,1]$. Since $\left.\frac{d F_{B t}}{d F_{A t}}\right|_{d W_{t}=0}=-\left(\frac{F_{B t}}{F_{A t}}\right)^{1-\sigma}$, the parameter $\sigma$ measures the normatively determined trade-off between efficiency (the level of total pay-off) and inter-community, or horizontal, equity (the distribution of pay-offs): a higher value of $\sigma$ implies that a marginal reduction in income for the poorer community (say A) has to be attended by a lower increase in the income of the richer community to keep social welfare invariant. Hence, higher $\sigma$ implies greater privileging of efficiency over horizontal equity. In the limiting case of $\sigma=1$, the privileging of efficiency to the complete exclusion of equity considerations, maximizing social welfare simply entails maximizing total pay-off, and therefore, minimizing conflict. It is well known that $\lim _{\sigma \rightarrow 0} W_{t}=\left(F_{A t} F_{B t}\right)^{\frac{1}{2}}$; thus, the geometric mean, or Cobb-Douglas, is generated as another limiting case. Furthermore, $\lim _{\sigma \rightarrow-\infty} W_{t}=\min \left\{F_{A t}, F_{B t}\right\}$, so that the Rawlsian maximin criterion, which privileges equity to the exclusion of efficiency considerations altogether, comprises a third limiting case. The elasticity of substitution is given by $\tau=\frac{1}{1-\sigma}$, so that $\tau \in(0,1) \cup(1, \infty]$, with greater elasticity intuitively implying a stronger emphasis on efficiency considerations, relative to equity.

To concentrate on the welfare properties of the conflict process and the distribution of contested income, and for ease of exposition, we shall ignore non-contestable resources, i.e., assume that, for all $t, M_{A t}=M_{B t}=0$. Then, recalling (15), and assuming, for notational simplicity, that the two communities have identical valuations (i.e. $p_{A}=p_{B} \equiv p$ ),

$$
\frac{W_{t}}{p}=\left(\frac{\left(s_{B A, t}\right)^{2 \sigma}+1}{\left[s_{B A, t}+1\right]^{2 \sigma}}\right)^{\frac{1}{\sigma}}
$$

Since the relative share depends on the relative, not absolute, cost of conflict (recall (12)-(13)), social welfare is independent of equi-proportionate changes in conflict costs. Only changes in conflict costs that affect one community disproportionately, thereby altering the relative conflict cost, can affect social welfare. Now, noting Corollary 1 , the steady state level of social welfare, $W_{S}$, is given by:

$$
W_{S}=p\left(\frac{s_{B A, 0}{ }^{2 \sigma} \bar{C}_{A B} \frac{2 \sigma}{1-\theta}+1}{\left[s_{B A, 0} \bar{C}_{A B}^{\frac{1}{1-\theta}}+1\right]^{2 \sigma}}\right)^{\frac{1}{\sigma}}
$$

Using (19), we get the following.

Proposition 3. Let Assumption 1 hold, and suppose $p_{A}=p_{B} \equiv p$. Then:

(i) steady state social welfare is decreasing (resp. increasing) in $\theta$ if [ $\sigma<\left(\right.$ resp. $>$ ) $\frac{1}{2}$ and $s_{B A, 0} \bar{C}_{A B} \geq$ 1]; it is initially increasing (resp. decreasing) and subsequently decreasing (resp. increasing) in $\theta$ 
over $(0,1)$ if $\left[\sigma<(\right.$ resp. $>) \frac{1}{2}$ and $\left.s_{B A, 0} \bar{C}_{A B}<1\right]$, the maximum (resp. minimum) being given by $\left[s_{B A, 0} \bar{C}_{A B} \frac{1}{1-\theta}=1\right]$;

(ii) steady state social welfare is decreasing (resp. increasing) in $\bar{C}_{A B}$ if $\left[\sigma<\left(\right.\right.$ resp. $>$ ) $\frac{1}{2}$ and $s_{B A, 0} \geq$ 1]; it is initially increasing (resp. decreasing) and subsequently decreasing (resp. increasing) in $\bar{C}_{A B}$ over $(1, \infty)$ if $\left[\sigma<(\right.$ resp. $>) \frac{1}{2}$ and $\left.s_{B A, 0}<1\right]$, the maximum (resp. minimum) being given by $\left[s_{B A, 0} \bar{C}_{A B}{ }^{\frac{1}{1-\theta}}=1\right]$;

(iii) steady state social welfare is initially increasing (resp. decreasing) and subsequently decreasing (resp. increasing) in $s_{B A, 0}$ over $(0, \infty)$ if $\left[\sigma<(\right.$ resp. $\left.>) \frac{1}{2}\right]$, the maximum (resp. minimum) being given by $\left[s_{B A, 0} \bar{C}_{A B}{ }^{\frac{1}{1-\theta}}=1\right]$.

Proof: See the Appendix.

The central message of Proposition 3 is that steady state social welfare behaves in a non-monotone fashion, with regard to all three policy parameters in the model, if the initial settlement $s_{B A, 0}$ more than negates a community's cost advantage. Starting from an original situation of perfect rigidity $(\theta=0)$, and an initial settlement that more than negates B's structural cost advantage, greater institutional flexibility initially reduces steady state inequality (by improving B's relative share), but increases steady state conflict. Eventually, a point of equal shares is reached. Beyond this threshold, however, further increases in institutional flexibility increase inequality (as B achieves greater dominance), while reducing conflict. Suppose equity is privileged to a great extent, so that the elasticity of substitution is less than 2 . Then social welfare initially rises and subsequently falls with increases in institutional flexibility. The opposite holds when efficiency is privileged more, so that the elasticity of substitution is greater than 2. Similar mechanisms operate for changes in the relative cost and the initial settlement. Notice that, when equity is privileged more, so that the elasticity of substitution is less than 2, the welfare maximizing level of any one of the three variables is lower, the higher the other two variables. Conversely, when efficiency is privileged more, the welfare minimizing level of any one of the three variables is lower, the higher the other two variables. It follows that, in the first case, setting high values of all three variables constitutes an incoherent policy package, but such generalized high values constitute a coherent policy package in the second case. Since social welfare converges to its steady state level (Proposition 1), results analogous to those in Proposition 3 must hold for every period subsequent to the passage of some finite number of periods. 
Remark 5. Proposition 3(i) supports perfect institutional rigidity $(\theta=0)$ as welfare maximizing if horizontal equity is privileged over efficiency, so that the elasticity of substitution is less than 2, and an equal initial settlement $\left(s_{B A, 0}=1\right)$ is imposed, but not in general. However, by Proposition 3(iii), given the privileging of horizontal equity, and perfectly rigid institutions, social welfare is maximized by an unequal initial settlement $\left(s_{B A, 0}<1\right)$. Thus, the welfare argument for a policy package which combines perfect institutional rigidity with an equal initial settlement, and, by implication, for inter-temporally persistent institutional neutrality, appears incoherent.

Lastly, what happens to social welfare outside the steady state when the system receives a onetime shock to the relative share or a permanent shock to either the relative cost or the extent of institutional flexibility? How does social welfare adjust dynamically to such shocks?

Proposition 4. Let Assumption 1 hold, and let $p_{A}=p_{B} \equiv p$. Then:

(i) if $\left[s_{B A, 0}\left(\bar{C}_{A B}\right)^{\left(\frac{1}{1-\theta}\right)} \leq 1\right]$ then $W_{t}$ is monotonically decreasing (resp. increasing) over time, with $\left[\frac{\partial W_{t}}{\partial s_{B A, 0}}, \frac{\partial W_{t}}{\partial \theta}, \frac{\partial W_{t}}{\partial \bar{C}_{A B}}<(\right.$ resp. $>) 0$ for $\left.t \geq 2\right]$, when $\sigma>($ resp. $<) 1 / 2$;

(ii) if $\left[s_{B A, 0} \bar{C}_{A B} \geq 1\right]$, then $W_{t}$ is monotonically increasing (resp. decreasing) over time, with $\left[\frac{\partial W_{t}}{\partial s_{B A, 0}}, \frac{\partial W_{t}}{\partial \theta}, \frac{\partial W_{t}}{\partial \bar{C}_{A B}}>(\right.$ resp. $<) 0$ for $\left.t \geq 2\right]$, when $\sigma>(\text { resp. }<)^{1 / 2}$;

(iii) if $\left[s_{B A, 0} \bar{C}_{A B}{ }^{1+\theta}<1, s_{B A, 0}\left(\bar{C}_{A B}\right)^{\left(\frac{1}{1-\theta}\right)}>1\right]$, then there exists $t^{*} \in\{3,4,5, \ldots\}$ such that: (a) $W_{t}$ decreases with time over $\left[1, t^{*}\right)$ and increases over $\left(t^{*}, \infty\right)$, with $\left[\frac{\partial W_{t}}{\partial s_{B A, 0}}, \frac{\partial W_{t}}{\partial \theta}, \frac{\partial W_{t}}{\partial \bar{c}_{A B}}<\right.$ (resp. $>$ ) 0 if $t<\left(\right.$ resp. $>$ ) $t^{*}$ and $\left.t \geq 2\right]$, when $\sigma>1 / 2$; and (b) $W_{t}$ increases with time over $\left[1, t^{*}\right)$ and decreases over $\left(t^{*}, \infty\right)$; with $\left[\frac{\partial W_{t}}{\partial s_{B A, 0}}, \frac{\partial W_{t}}{\partial \theta}, \frac{\partial W_{t}}{\partial \bar{c}_{A B}}>(\right.$ resp. $<) 0$ if $t<($ resp. $>) t^{*}$ and and $\left.t \geq 2\right]$ when $\sigma<1 / 2$.

Proof: See the Appendix.

Note that that the claims made in Proposition 4 with regard to $\frac{\partial W_{t}}{\partial s_{B A, 0}}, \frac{\partial W_{t}}{\partial \bar{C}_{A B}}$ actually hold for all $t \geq 1$. Suppose $\sigma>1 / 2$ (the elasticity of substitution exceeds 2), so that the social welfare function does not privilege equity too highly. By Assumption 1, B has a secular cost advantage. Consider an initial settlement that is large enough to counter-act B's cost-advantage completely, so that it suffices to depress B's share below that of A in the steady state, and therefore, in every period. Then B's share increases monotonically over time, as B's cost advantage partially, but increasingly, negates the 
adverse initial settlement. By Proposition 4(i), social welfare must then be above its steady state level in every period, monotonically declining to asymptotically converge to the latter. The lower the initial relative share of $\mathrm{B}$, the lower the level of conflict (though the more unequal the distribution), hence the higher the social welfare in each period. Conversely, if the initial settlement only attenuates B's cost advantage without reversing it, so that B receives the higher share even in period 1, then, by Proposition 4(ii), social welfare must be below its steady state level in every period, monotonically increasing to asymptotically converge to the latter. The higher the initial share of $\mathrm{B}$, the lower the level of conflict, thus the higher the social welfare in each period. Opposite conclusions follow if the social welfare function privileges equity to a great extent (the elasticity of substitution is less than 2). The case with shocks to either the relative cost or the degree of institutional flexibility is identical. Proposition 4(iii) considers the intermediate case, where the initial shock is large enough to move B's share below that of $\mathrm{A}$ in at least the first two periods, but is not enough to counteract B's cost advantage in later periods. Social welfare and the impact of the initial share on it both then move in a non-monotone fashion, as specified in Proposition 4(iii). The welfare impacts of shocks to either the relative cost or the degree of institutional flexibility are likewise non-monotone.

Remark 6. By Proposition 4(ii), perfect institutional neutrality $\left(s_{B A, 0}=1\right.$ and $\left.\theta=0\right)$ cannot be the optimal policy package irrespective of whether $\sigma>\frac{1}{2}$ or $<\frac{1}{2}$. In the first case, welfare is improved by increasing both $s_{B A, 0}$ and $\theta$ beyond 1 and 0 , respectively. In the second, it is maximized by $s_{B A, 0} \bar{C}_{A B}=1$ (which implies $\theta<1$ ) and $\theta=0$. Thus, efficiency is improved both by institutional augmentation of B's cost advantage and institutional responsiveness to ethnic pressure. Conversely, horizontal equity is maximized by perfectly rigid institutions combined with an initial settlement that disadvantages B to the extent that exactly neutralizes B's cost advantage. Thus, like Proposition 3 (Remark 5), Proposition 4 suggests that the case for perfect institutional neutrality is questionable.

Since all relevant functions are continuous, results qualitatively identical to Propositions 3-4 hold even when the two communities differ in their valuation of the contested resource. The threshold value of the elasticity of substitution, with regard to which these results are articulated, now comes to differ from 2, with its magnitude depending on the exact relative valuation of the contested resource.

\section{Discussion}

The analysis above carries important implications for understanding the connections between an initial institutional settlement brought about by historical shocks (colonialism, foreign intervention or an authoritarian regime), institutional ethnicization and the subsequent co-evolution of conflict and horizontal inequality within a society. Suppose we observe persistent and increasing conflict between 
ethnic groups over resource sharing. Our model would rationalize this either as a permanent phenomenon, in terms of the parametric configuration $\left[\mathrm{s}_{\mathrm{BA}, 0}\left(\overline{\mathrm{C}}_{\mathrm{AB}}\right)^{\left(\frac{1}{1-\theta}\right)} \leq 1\right]$ (Corollary 2(ii)) or as a transient one, in terms of $\left[\mathrm{s}_{\mathrm{BA}, 0} \overline{\mathrm{C}}_{\mathrm{AB}}\left(\frac{1}{1-\theta}\right)>1\right.$ and $\left.\mathrm{s}_{\mathrm{BA}, 0} \overline{\mathrm{C}}_{\mathrm{AB}}{ }^{1+\theta}<1\right]$ (Corollary 2(iii)). Suppose the policy objectives can be aggregated in terms of the normative adoption of an elasticity of substitution greater than 2. In the first case, Proposition 4(i) would imply that a one-time shock to the relative success ratio by an external agent such as the UN, NATO or other multi-lateral agencies, or some foreign government(s), that reduces B's share marginally below that prevailing on the adjustment path in some time period, say through a one-off subsidization of A's military expenses in that period, or through direct politico-military intervention, is likely to permanently reduce conflict. Institutional reforms that make institutions less responsive to immediate ethnic pressures (lower $\theta$ ), say by permanently freezing the ethnic composition of large segments of the administrative apparatus at its current pattern, would further reduce conflict and improve social welfare. Both these interventions would however permanently worsen horizontal equity. Hence, they would be opposed by those who normatively privilege horizontal equity over conflict reduction, to the extent of, in effect, espousing an elasticity of substitution less than 2. For both groups, however, the policy stance would be time invariant, given their normative prior (i.e., elasticity of substitution). Thus, policy disagreements would hinge entirely on normative differences in the valuation of equity vis-à-vis efficiency, as formalized by differences in the elasticity of substitution chosen for policy valuation.

This policy clarity however disappears in the second, arguably empirically more common, case where the initial historical settlement imposed say by a colonial power is large enough to convert the dominant community (the one with a secular cost advantage) into the dominated one (in the sense of receiving the lower share) in the initial periods, but not large enough to do so permanently. By Proposition 4(iii), in the absence of further intervention, social welfare would evolve, over time, according to the unbroken schedule in Figure 1 below, given the normative privileging of efficiency over horizontal equity. As the relative share of B increases over time, reflecting this community's secular cost advantage, conflict first rises, reducing social welfare, as the relative share approaches unity. Beyond this, as B increases its share more and more over A, conflict falls, increasing social welfare. Thus, the time path of social welfare exhibits the U-shape portrayed in Figure 1 below.

\section{Figure 1 here.}

Conflict increases over time, reducing social welfare, till $t^{*}$, and decreases subsequently, increasing welfare. For those prioritizing conflict reduction, a case for policy intervention may thus be perceived if the society is observed before $t^{*}$. Suppose this leads to an intervention in period $\dddot{t}$, which, as earlier, takes the form of a marginal reduction of B's share below its adjustment path and/or a reduction in the degree of institutional flexibility. Then, by Proposition 4(iii), the society permanently 
shifts to a new adjustment path, portrayed by the broken schedule in Figure 1. Conflict is lower (and thus social welfare higher) along the new adjustment path, relative to the old, for the initial periods (till $t^{*}$ ). However, conflict is higher (and thus social welfare lower) along the new adjustment path in every period after $t^{*}$. Steady state social welfare declines from $W_{S}$ to $\dddot{W}_{S}$. The aggregate welfare consequence of the intervention is thus ambiguous: it depends both on the exact time path and the time discount factor adopted. When the elasticity of substitution is less than 2, the welfare schedule has an inverted U-shape, with the welfare implications of the intervention getting exactly reversed. Thus, one can no longer generate an unambiguous welfare ranking of policy interventions on the basis of their magnitude purely from the elasticity of substitution: this additionally requires explicit intertemporal trade-offs. Furthermore, an element of time inconsistency gets built into the policy debate. Clearly, an ex post assessment of the intervention, in terms of its present and future consequences, made much after the event, may take a very different view than an ex ante assessment, even when they share the same normative presupposition (same elasticity) and the same time discount factor.

Interventions in conflict zones by foreign entities are often politically justified by the jointly stated goal of conflict reduction and protection of weaker ethnic groups, within a context of growing ethnic conflict. Based on a cross-national, time-series data analysis of 164 countries for the years 1981 to 2005, Choi and James (2014) find that, ceteris paribus, the US is likely to engage in military campaigns for humanitarian reasons rather than for its own security interests. Politicians and voters in liberal democracies which are in a position to intervene are likely to prioritize immediate conflict reduction over long-term peace building. As discussed above, higher levels of short term peace and protection of weaker ethnic groups may be ensured by one-off interventions which impose a combination of higher institutional disadvantage and greater institutional rigidity on the ethnic group with a conflict cost advantage. However, such higher levels of short term conflict reduction are purchased at the cost of deeper conflict in the longer term. Thus, political short-termism in intervening liberal democracies is likely to bias peace-building interventions towards forms (specifically, greater institutional locking out of the stronger/dominant group post intervention and greater institutional rigidity with regard to emergent ethnic political pressure) that are likely to exacerbate conflict in the future. Such exacerbation in turn is likely to justify demands for repeated and deeper intervention, as has been the case in Iraq, Syria and Afghanistan, which would push the problem even further into the future. Thus, our model suggests that external interventions, when effective in reducing current conflict and protecting weaker groups, may in fact end up sowing the seeds of greater future conflict and further external intervention. Interventions by liberal democracies in conflicted societies may therefore turn out to be self-reinforcing and self-replicating.

Ethnocratic settlements often form the key feature of peace deals to end civil wars, and are commonly imposed by colonial regimes, militarily superior external powers or multilateral agencies. 
As discussed in Section 1, recent settlements in Bosnia, Northern Ireland, Lebanon, Iraq and Afghanistan provide examples. In many other countries fragmented along ethnic lines, one may perceive such settlements developing gradually and internally as an outcome of domestic ethnic politics. Our analysis clarifies one reason for the popularity of such settlements: they may function as a commitment device. As shown in Propositions 1 and 2, relatively rigid institutions, combined with an initial settlement favourable to the group that is weaker (high cost) in conflict, may lead to that group's resource share granted to it by state institutions remaining relatively high indefinitely into the future. This might increase the weaker group's incentive to remain within the state system, i.e., engage with the institutionalized rules of conflict settlement and negotiation, instead of rejecting it altogether in favour of an all-out insurgency or civil war. However, the absence of all out civil war does not imply the absence of conflict: working within institutions also generates ethnic conflict over rent-seeking attempts to influence the functioning of those institutions. Such conflicts may take the form of litigation, lobbying, mass political mobilization, as well as selective use of violence.

The greater the weaker ethnic group's expected outcome in case of civil war and state breakdown, the higher the steady-state pay-off this group has to be offered to induce its members to accept a lasting institutional settlement: hence, the more biased the initial settlement has to be against the stronger (cost advantaged) ethnic group and the more rigid the consequent institutions (recall Corollary 1). ${ }^{13}$ For example, the settlement imposed by France in Lebanon at independence was heavily biased in favour of the Maronite Christian minority, that adopted in Yugoslavia under Tito advantaged smaller groups such as the Slovenes, Bosniaks and Albanians (especially from the late 1960s), and 'de-Baathification' imposed by the US occupation authority led to the replacement of large numbers of Sunnis from positions of power within the state apparatus (especially the security forces by Shias even in the Sunni-majority areas. We are thus likely to observe a settlement which leads to rising rent-seeking conflict within a structure of formal ethnic peace and acceptance of civic institutions, at least in the initial periods subsequent to the settlement (Recall Proposition 4 parts (i) and (iii)). Indeed, inter-ethnic rent-seeking conflict would remain high even in the steady state. Thus, formal peace, when purchased through an ethnocratic settlement, runs the risk of locking the society into a permanent state of high rent-seeking conflict around rigid identitarian mobilizations. This, arguably, characterized Yugoslavia in the post-Tito period before the onset of war, and is the reality of societies such as Bosnia, Lebanon, Northern Ireland and Belgium today. Furthermore, to the extent that high and persistent rent-seeking conflict has a tendency to develop a momentum and dynamic of

\footnotetext{
${ }^{13}$ There is, for example, evidence that minority ethnic groups are more prone to insurrection if concentrated in rural areas, as opposed to being dispersed around the country (Jenne et al. (2007), Toft (2003)). Ethnocratic settlements would have to offer such groups a large institutional share to induce them to accept state institutions, as typically happens in practice through regional autonomy and constitutional rules determining fiscal transfers.
} 
its own, it may tip over into full-blown civil war and external intervention, as happened for example in Lebanon between 1975 and 1990, Yugoslavia in the 1990s and is currently happening in Iraq. ${ }^{14}$

\section{Concluding remarks}

This paper has developed a simple model of dynamic ethnic conflict when state institutions exhibit evolving ethnic bias. Our main results involve the non-monotone nature of the relationship between conflict, distribution and social welfare on one hand, and key peace policy variables, such as the ethnic bias of an initial institutional division and the responsiveness of such bias to emerging political pressure from mass ethnic movements, on the other. These findings may be seen as highlighting the fundamental limitation of ethnocratic settlements as peace-building devices in conflict-ridden societies. Our analysis suggests that, when successful in avoiding all-out civil war and state collapse, such ethnocratic settlements are likely to generate high levels of conflict over ethnic rent-seeking, within the framework of a fragile state perpetually susceptible to external interference and intervention. This 'ethnocratic trap' (Howard, 2012) can be avoided only by developing more inclusive, porous and flexible forms of identity formation and integrative institutions that cut across rigid ethnic divides (see Dasgupta and Kanbur (2005b) for a formal model that expands on this idea).

Our analysis of course has a number of limitations and may be extended in various directions. We have abstracted from group size effects. A suitably amended version of the model with convex effort cost (as, for example, in Esteban and Ray (2001)) would allow one to incorporate this aspect and explicitly investigate majority-minority issues. Furthermore, we have assumed an egalitarian surplus sharing rule within both communities. Different, and possibly asymmetric, sharing rules within the contending groups (e.g. Davis and Reilly (1999) and Nitzan (1991)) will in general generate different dynamic patterns of conflict and distribution. One may also explicitly model an additional contest within each community for sharing of the prize in every period, either simultaneously with the original inter-community contest (expanding the one-period structure in, for example, Dasgupta (2009)), or subsequent to it (along the lines of Katz and Tokatlidu (1996)). Acemoglu and Wolitzky (2014) have developed a model of conflict cycles generated by coordination problems due to incomplete information regarding the nature of groups different from one's own. An extension of our model can generate conflict cycles endogenously even in our complete information set-up. We have assumed that conflict input costs are constant over time. One may instead assume that each community invests a constant proportion of its net income in every period, and that the

${ }^{14}$ Countries with a civil war in the past are much more likely to experience another one (Collier and Hoffler, 2004). Collier et al. (2004) find that, in about $40 \%$ of the cases they study, civil war recurs within a decade. To the extent that ethnocratic settlements accompanied the end of civil war in many of these countries, our results provide one rationalization of these findings. 
opportunity cost of activist labour increases with community-specific investment in the preceding period, due to a consequent increase in the community's labour productivity in income generating non-expropriatory activities. It is easy to see that the relative conflict cost may then exhibit cyclical movement, generating conflict cycles. All these extensions may be usefully addressed in future work.

\section{References}

Acemoglu, D. and A. Wolitzky (2014): "Cycles of conflict: an economic model", American Economic Review 104(4): 1350-67.

Arbatskaya, M. and H.M. Mialon (2010): "Multi-activity contests", Economic Theory 43: 23-43.

Baik, K. \& S. Lee (2000): "Two-stage rent-seeking contests with carryovers", Public Choice 103: 285-296.

Callander, S. (2007): "Bandwagons and momentum in sequential voting", Review of Economic Studies 74: 653-684.

Choi, S.W. and P. James (2014): "Why does the United States intervene abroad? Democracy, human rights violations and terrorism", Journal of Conflict Resolution (forthcoming): doi:10.1177/0022002714560350.

Collier, P. and A. Hoeffler (2004): "Greed and grievance in civil wars", Oxford Economic Papers 56: 563-95.

Collier, P., A. Hoeffler and M. Soderbom (2004): "On the duration of civil war", Journal of Peace Research 41(3): 253-73.

Dasgupta, I. (2009): “'Living' wage, class conflict and ethnic strife”, Journal of Economic Behavior and Organization 72(2): 750-765.

Dasgupta, I. and R. Kanbur (2011): “Does philanthropy reduce inequality?”, Journal of Economic Inequality 9(1): 1-21.

Dasgupta, I. and R. Kanbur (2007): “Community and class antagonism”, Journal of Public Economics 91(9): 1816-1842.

Dasgupta, I. and R. Kanbur (2005a): “Community and anti-poverty targeting”, Journal of Economic Inequality 3(3): 281-302.

Dasgupta, I. and R. Kanbur (2005b): "Bridging communal divides: separation, patronage, integration", in C. Barrett (ed.) The Social Economics of Poverty: On Identities, Groups, Communities and Networks. London: Routledge; 146-170.

Davis, D. and R. Reilly (1999): "Rent-seeking with non-identical sharing rules: an equilibrium rescued", Public Choice 100(1-2): 31-8.

Esteban, J. and D. Ray (2001): "Collective action and the group size paradox", American Political Science Review 95(3): 663-72.

Hardin, R. (1982): Collective Action; Baltimore, Md.: Johns Hopkins University Press.

Howard, L.M. (2012): "The ethnocracy trap", Journal of Democracy 23(4): 155-169. 
Irfanoglu, Z.B., S.D. Mago and R.M. Sheremeta (2014): "The New Hampshire effect: behavior in sequential and simultaneous election contests", Working Papers 14-15, Chapman University, Economic Science Institute.

Jenne, E.K., S. M. Saideman and W. Lowe (2007): "Separatism as a bargaining posture: the role of leverage in minority radicalization", Journal of Peace Research 44(5): 539-58.

Katz, E., S. Nitzan and J. Rosenberg (1990): "Rent-seeking with pure public goods", Public Choice 65(1): 49-60.

Katz, E. and J. Tokatlidu (1996): "Group competition for rents", European Journal of Political Economy 12(4): 599-607.

Kedar, A.S. (2003) : "On the legal geography of ethnocratic settler states: notes towards a research agenda", in J. Holder and C. Harrison (eds.) Law and Geography: Current Legal Issues Volume 5. Oxford: Oxford University Press; 401-441.

Klumpp, T. and M.K. Polborn (2006): "Primaries and the New Hampshire effect", Journal of Public Economics 90: 1073-1114.

Konrad, K.A. (2009): Strategy and Dynamics in Contests; Oxford: Oxford University Press.

Konrad, K.A., and D. Kovenock (2009): "Multi-battle contests", Games and Economic Behavior 66: 256-274.

Kovenock, D. and B. Roberson (2012): "Conflicts with multiple battlefields", in M. Garfinkel and S. Skaperdas (eds.) The Oxford Handbook of the Economics of Peace and Conflict. Oxford: Oxford University Press; 503-531.

Kvasov, D. (2007): "Contests with limited resources", Journal of Economic Theory, 136: 738-748.

Lee, S. (2003): "Two-stage contests with additive carryovers", International Economic Journal 17(1): 83-99.

Maxwell, J.W. and R. Reuveny (2005): "Continuing conflict", Journal of Economic Behavior and Organization 58(1): 30-52.

Nitzan, S. (1991): "Rent-seeking with nonidentical sharing rules", Public Choice 71(1-2): 43-50.

Olson, M. (1965): The Logic of Collective Action; Cambridge; MA: Harvard University Press.

Reuveny, R., J. W. Maxwell and J. Davis (2011): "Dynamic winner-take-all conflict", Defence and Peace Economics 22(5): 471-492.

Schmitt, P., R. Shupp, K. Swope, and J. Cadigan (2004): "Multi-period rent-seeking contests with carryover: Theory and Experimental Evidence", Economics of Governance 10, 247-259.

Toft, M.D. (2003): The Geography of Ethnic Violence: Identity, Interests, and the Indivisibility of Territory; Princeton: Princeton University Press.

Tullock, G. (1980): "Efficient rent seeking", in J.M. Buchanan, R.D. Tollison, and G. Tullock (eds.), Toward a theory of the rent-seeking society. College Station: Texas A\&M University Press; 97-112.

Varma, S. (2012): " SC/STs fail to break caste ceiling: No SC in 149 top government officers, 40 pc do menial jobs", The Economic Times, Sept. 6, 2012; (http://articles.economictimes.indiatimes.com/2012-09-06/news/33650235_1_sc-officersbacklog-posts-ias-officers). 
Yiftachel, O. and A. Ghanem (2004): "Understanding 'ethnocratic' regimes: the politics of seizing contested territories", Political Geography 23 (6): 647-676.

Yiftachel, O. (2006): Ethnocracy: Land and Identity Politics in Israel/Palestine; Philadelphia: University of Pennsylvania Press.

\section{Appendix}

\section{Proof of Proposition 2.}

Recall that $\bar{C}_{A B}>1$ by Assumption 1, and note that $\left(\frac{1-\theta^{t}}{1-\theta}\right)=\left(1+\theta+\cdots+\theta^{t-1}\right)$. Part (i) of Proposition 2 follows from (12) and (15). Part (ii) of Proposition 2 follows from (13) and Corollary 1. Now recall that, by (12), $s_{B A, 1}=s_{B A, 0} \bar{C}_{A B}, s_{B A, 2}=s_{B A, 0}\left(\bar{C}_{A B}\right)^{(1+\theta)}$, and, by Proposition $1, s_{B A, t}$ is monotonically increasing in time. Hence, if $s_{B A, 0} \bar{C}_{A B}{ }^{1+\theta}>1, s_{B A, t}>1$ for all $t \geq 2$. Conversely, recalling Proposition 1 , if $s_{B A, 0} \bar{C}_{A B}{ }^{\frac{1}{1-\theta}} \leq 1$ then $s_{B A, t}<1$ for all $t \geq 1$. If $\left[\mathrm{s}_{\mathrm{BA}, 0} \bar{C}_{A B}{ }^{1+\theta}<1\right.$ and $s_{B A, 0} \bar{C}_{A B} \frac{1}{1-\theta}>1$ ], then there exists $\mathrm{t}^{*} \in\{3,4, \ldots\}$ such that $s_{B A, t}<1$ (resp. $>1$ ) if $\mathrm{t}<$ (resp. $>$ ) $\mathrm{t}^{*}$. From (16), $\frac{\partial E_{t}}{\partial s_{B A, t}}>0$ if $s_{B A, t} \in(0,1)$, and $\frac{\partial E_{t}}{\partial s_{B A, t}}<0$ if $s_{B A, t}>1$. Recalling that, by (12), $\frac{\partial s_{B A, t}}{\partial \theta}>0$ Proposition 2(iii) follows. Part (iv) of Proposition 2 follows from (17).

\section{Proof of Proposition 3.}

Using (19), and taking a positive monotone transformation,

$$
\begin{aligned}
& W_{S}=\left(\frac{1}{s_{B A, 0} \bar{C}_{A B} \frac{1}{1-\theta}+1}\right)^{2 \sigma}+\left(\frac{s_{B A, 0} \bar{C}_{A B} \frac{1}{1-\theta}}{s_{B A, 0} \bar{C}_{A B} \frac{1}{1-\theta}+1}\right)^{2 \sigma} \\
& \left.\frac{\partial W_{S}}{\partial \theta}=\left(\frac{s_{B A, 0}}{\left[s_{B A, 0} \bar{C}_{A B}^{\frac{1}{1-\theta}}+1\right]^{2}}\right)\left[\dddot{W}^{\prime}\left(\frac{s_{B A, 0} \bar{C}_{A B}^{\frac{1}{1-\theta}}}{\left[s_{B A, 0} \bar{C}_{A B} \frac{1}{1-\theta}+1\right.}\right]\right)-\dddot{W}^{\prime}\left(\frac{1}{s_{B A, 0} \bar{C}_{A B} \frac{1}{1-\theta}+1}\right)\right] \frac{\partial\left(\bar{C}_{A B}^{\frac{1}{1-\theta}}\right)}{\partial \theta} ;
\end{aligned}
$$

where $\dddot{W}(z)=z^{2 \sigma}$. Clearly, if $\sigma<($ resp. $>) \frac{1}{2}$, then $\left[\dddot{W}^{\prime}\left(z_{1}\right)<\dddot{W}^{\prime}\left(z_{2}\right)\right.$ iff $z_{1}>$ (resp. $\left.\left.<\right) z_{2}\right]$. Now, $s_{B A, 0} \bar{C}_{A B} \frac{1}{1-\theta}>1$ for all $\theta \in(0,1)$ if $s_{B A, 0} \bar{C}_{A B} \geq 1$. Hence, if $\left[\sigma<\frac{1}{2}\right.$ and $\left.s_{B A, 0} \bar{C}_{A B} \geq 1\right]$, then $\left[\dddot{W}^{\prime}\left(\frac{s_{B A, 0} \bar{C}_{A B^{\frac{1}{1-\theta}}}}{\left[s_{B A, 0} \bar{C}_{A B^{\frac{1}{1-\theta}}+1}\right.}\right)-\dddot{W}^{\prime}\left(\frac{1}{s_{B A, 0} \bar{C}_{A B^{\frac{1}{1-\theta}}+1}}\right)\right]<0$ for all $\theta \in(0,1)$. Noting that $s_{B A, 0} \bar{C}_{A B}{ }^{\frac{1}{1-\theta}}>1$ for 
$\theta$ sufficiently close to 1 , and that $\bar{C}_{A B} \frac{1}{1-\theta}$ is monotonically increasing in $\theta$ (since $\bar{C}_{A B}>1$ by Assumption 1), if $\left[\sigma<\frac{1}{2}\right.$ and $\left.s_{B A, 0} \bar{C}_{A B}<1\right]$, there must exist $\theta^{*} \in(0,1)$ such that $\left[\dddot{W}^{\prime}\left(\frac{s_{B A, 0} \bar{C}_{A B^{\frac{1}{1-\theta}}}}{\left[s_{B A, 0} \bar{C}_{A B} \frac{1}{1-\theta}+1\right.}\right]-\dddot{W}^{\prime}\left(\frac{1}{s_{B A, 0} \bar{C}_{A B}^{\frac{1}{1-\theta}+1}}\right)\right]>($ resp. $<) 0$ if $\theta<\left(\right.$ resp. $>$ ) $\theta^{*}$. Part (i) of Proposition 3 follows for $\sigma<\frac{1}{2}$. The argument is symmetric for $\sigma>\frac{1}{2}$.

Recalling that $\bar{C}_{A B}>1$ by Assumption 1, parts (ii) and (iii) of Proposition 3 follow by arguments exactly analogous to that presented in the proof of part (i) of Proposition 3.

\section{Proof of Proposition 4.}

From the expression for per period social welfare ((18) above), we have:

$$
\frac{\partial W_{t}}{2 p \partial s_{B A, t}}=\left(\frac{\left(s_{B A, t}\right)^{2 \sigma}+1}{\left[s_{B A, t}+1\right]^{2 \sigma}}\right)^{\frac{1}{\sigma}-1}\left[\frac{\left(s_{B A, t}\right)^{2 \sigma-1}-1}{\left[s_{B A, t}+1\right]^{2 \sigma+1}}\right] .
$$

By (20),

$$
\begin{aligned}
& \text { when } \sigma>\frac{1}{2},\left[\frac{\partial W_{t}}{\partial s_{B A, t}}<0 \text { if } s_{B A, t} \in(0,1)\right] \text { and }\left[\frac{\partial W_{t}}{\partial s_{B A, t}}>0 \text { if } s_{B A, t}>1\right] \text {; when } \sigma<\frac{1}{2},\left[\frac{\partial W_{t}}{\partial s_{B A, t}}>0\right. \\
& \text { if } \left.s_{B A, t} \in(0,1)\right] \text { and }\left[\frac{\partial W_{t}}{\partial s_{B A, t}}<0 \text { if } s_{B A, t}>1\right] \text {. }
\end{aligned}
$$

Furthermore, (20) yields:

$$
\frac{\partial W_{t}}{2 p \partial s_{B A, 0}}=\left(\frac{\left(s_{B A, t}\right)^{2 \sigma}+1}{\left[s_{B A, t}+1\right]^{2 \sigma}}\right)^{\frac{1}{\sigma}-1}\left[\frac{\left(s_{B A, t}\right)^{2 \sigma-1}-1}{\left[s_{B A, t}+1\right]^{2 \sigma+1}}\right] \frac{\partial s_{B A, t}}{\partial s_{B A, 0}} .
$$

Recall that, by (12), $s_{B A, t}=s_{B A, 0}\left(\bar{C}_{A B}\right)^{\left(\frac{1-\theta^{t}}{1-\theta}\right)}$. Thus, $\frac{\partial s_{B A, t}}{\partial s_{B A, 0}}>0$. Furthermore, from (20),

$$
\frac{\partial W_{t}}{2 \pi p \partial \theta}=\left(\frac{\left(s_{B A, t}\right)^{2 \sigma}+1}{\left[s_{B A, t}+1\right]^{2 \sigma}}\right)^{\frac{1}{\sigma}-1}\left[\frac{\left(s_{B A, t}\right)^{2 \sigma-1}-1}{\left[s_{B A, t}+1\right]^{2 \sigma+1}}\right] \frac{\partial s_{B A, t}}{\partial \theta} .
$$

By Proposition 2(i), for all $t \in\{2,3, \ldots\}, \frac{\partial s_{B A, t}}{\partial \theta}>0$. Now recall that, by (12), $s_{B A, t}$ is increasing over time and asymptotically converges to $s_{B A, 0}\left(\overline{\mathrm{C}}_{\mathrm{AB}}\right)^{\frac{1}{1-\theta}}$. Hence, if $\left[\mathrm{s}_{\mathrm{BA}, 0}\left(\overline{\mathrm{C}}_{\mathrm{AB}}\right)^{\left(\frac{1}{1-\theta}\right)} \leq 1\right]$, then [for all $t \geq 1, s_{B A, t}<1$. Conversely, noting that by (12), $s_{B A, 1}=s_{B A, 0} \bar{C}_{A B}$, [ $s_{B A, 0} \bar{C}_{A B} \geq 1$ ] implies [for all $\left.t \geq 2, \quad s_{B A, t}>1\right]$. Lastly, noting that by (12), $s_{B A, 2}=s_{B A, 0} \bar{C}_{A B}{ }^{1+\theta}$, if $\left[\mathrm{s}_{\mathrm{BA}, 0} \overline{\mathrm{C}}_{\mathrm{AB}}{ }^{1+\theta}<1, \mathrm{~s}_{\mathrm{BA}, 0}\left(\overline{\mathrm{C}}_{\mathrm{AB}}\right)^{\left(\frac{1}{1-\theta}\right)}>1\right]$, then there exists $\mathrm{t}^{*} \in\{3,4,5, \ldots\}$ such that $\left[s_{B A, t}<\right.$ (resp. $>$ ) 1 if $t<$ (resp.>) $t^{*}$. Using (20)-(23), we then get Proposition 4 . 
FIGURE 1

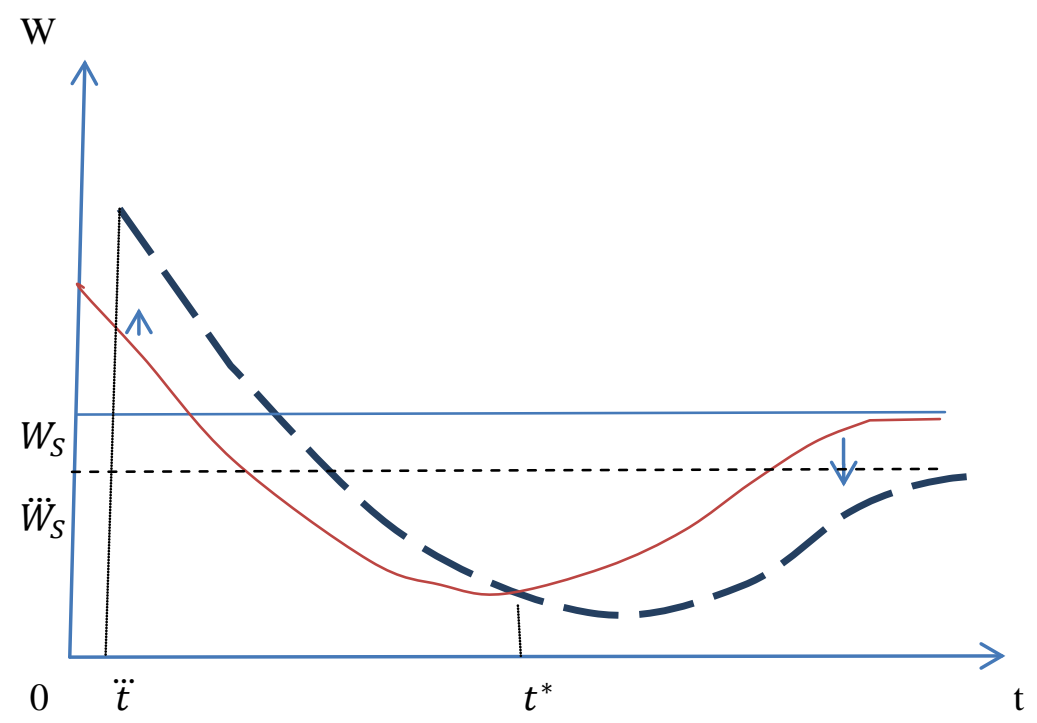

